L'église Saint-Pierre de La Chapelle-Lasson (Marne) : des fondations aux élévations. Apports d'un diagnostic archéologique

\title{
Cédric Roms
}

\author{
(2) OpenEdition \\ Journals \\ Édition électronique \\ URL : https://journals.openedition.org/cem/17907 \\ DOI : 10.4000/cem. 17907 \\ ISSN : 1954-3093 \\ Éditeur \\ Centre d'études médiévales Saint-Germain d'Auxerre
}

Référence électronique

Cédric Roms, «L'église Saint-Pierre de La Chapelle-Lasson (Marne) : des fondations aux élévations. Apports d'un diagnostic archéologique », Bulletin du centre d'études médiévales d'Auxerre I BUCEMA [En ligne], 24.2 | 2020, mis en ligne le 19 décembre 2020, consulté le 22 septembre 2022. URL : http:// journals.openedition.org/cem/17907 ; DOI : https://doi.org/10.4000/cem.17907

Ce document a été généré automatiquement le 22 septembre 2022.

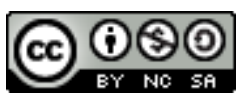

Creative Commons - Attribution - Pas d'Utilisation Commerciale - Partage dans les Mêmes Conditions 4.0 International - CC BY-NC-SA 4.0

https://creativecommons.org/licenses/by-nc-sa/4.0/ 


\section{L'église Saint-Pierre de La Chapelle- Lasson (Marne) : des fondations aux élévations. Apports d'un diagnostic archéologique}

Cédric Roms

La commune de La Chapelle-Lasson se situe dans le département de la Marne, à $13,5 \mathrm{~km}$ au sud-est de Sézanne dans une plaine alluvionnaire. L'église Saint-Pierre se trouve à l'extérieur de ce village de 85 habitants, au bord de la route menant à Marsangis (fig. 1) ${ }^{1}$. Autour d'elle, se développe un cimetière toujours utilisé.

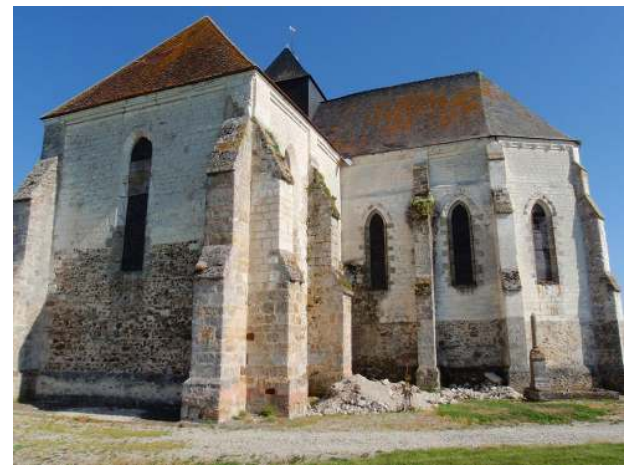


Fig. 1 - Vue du chevet et du transept sud (cl. C. Roms).

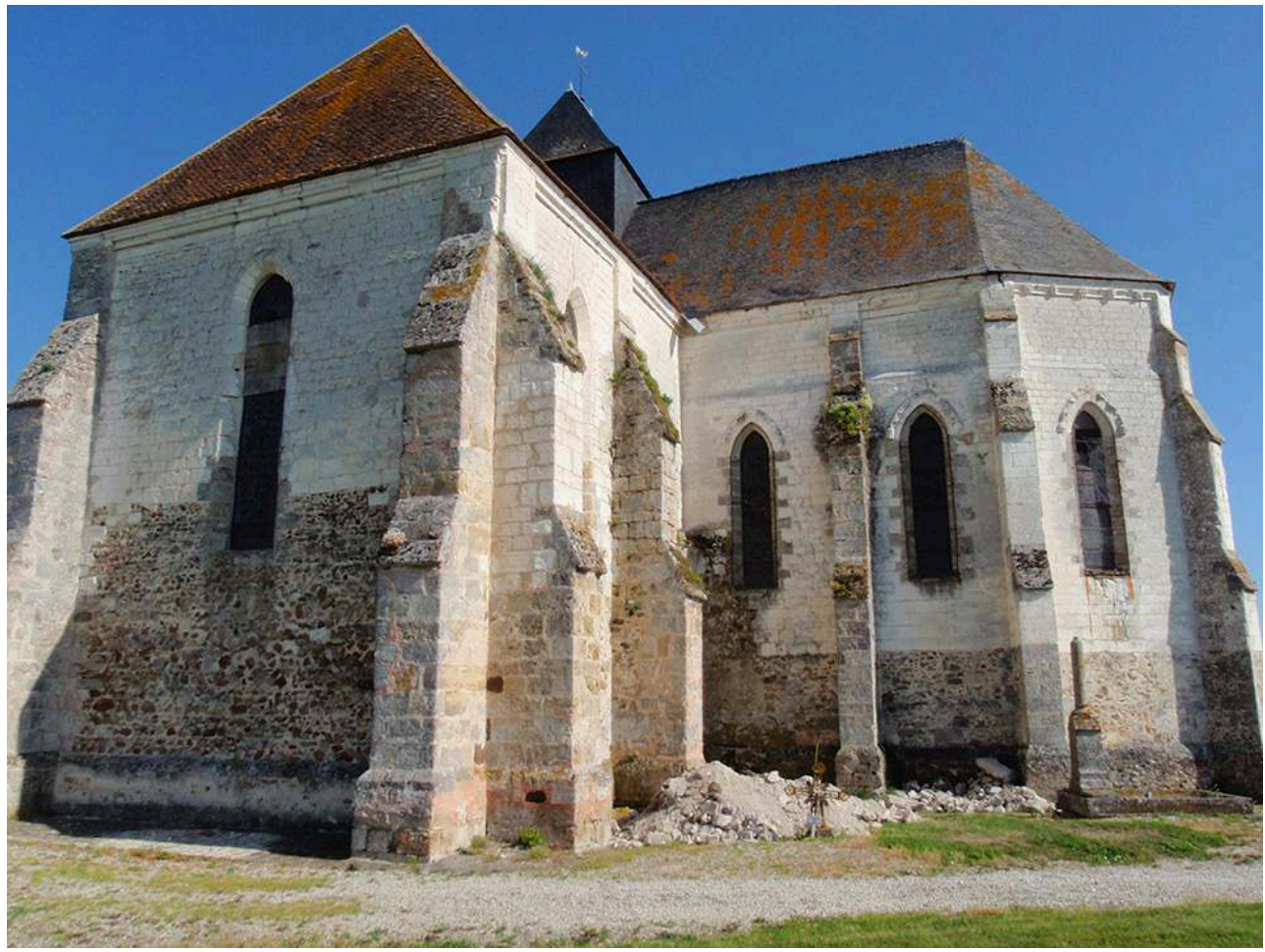

2 Un diagnostic archéologique a été réalisé sur le pourtour de l'église, avant l'aménagement d'un accès pour personnes à mobilité réduite et des travaux de restauration (fig. 2) ${ }^{2}$.

Fig. 2 - Plan des sondages et des structures (DAO D. Duda et C. Roms).

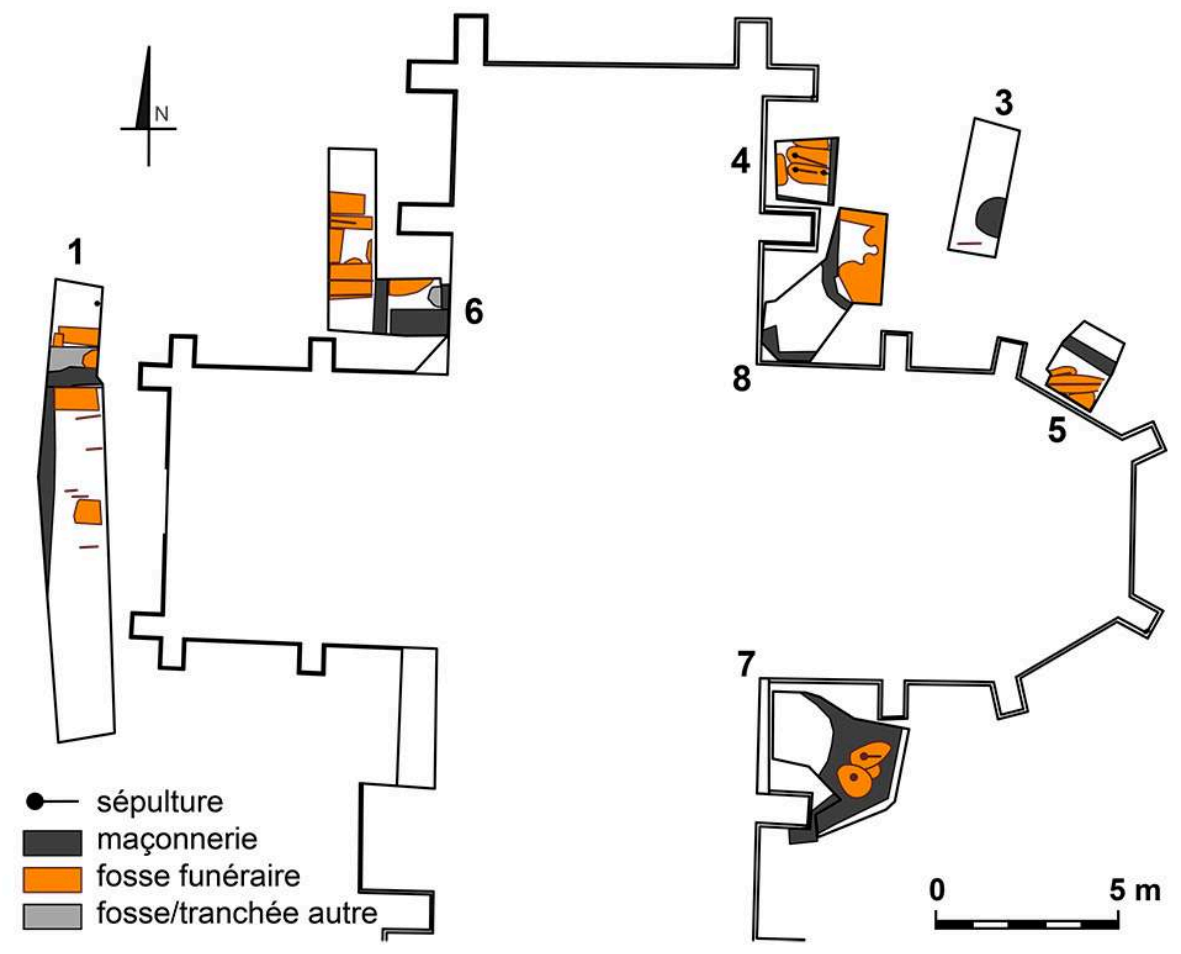


3 L'observation des maçonneries, en fondation comme en élévation, a permis de distinguer six états de construction qui se succèdent de la fin XII ${ }^{\mathrm{e}}$-début du XIII ${ }^{\mathrm{e}}$ siècle jusqu'à la fin du XIx ${ }^{e}$ siècle. La prescription ne portant pas sur les élévations, leur observation visuelle n'a été que superficielle; elle ne peut en aucun cas remplacer une étude complète du bâti. L'opération a cependant apporté de nombreux enseignements et répondu à certaines questions, tout en montrant l'intérêt d'un édifice encore trop méconnu, qui mériterait des recherches plus approfondies.

\section{Données architecturales}

4 Longue de $25 \mathrm{~m}$ et large de $22 \mathrm{~m}$, l'édifice est établi sur un plan en croix grecque orientée avec un chœur pentagonal précédé d'une travée droite; les deux bras du transept comptent deux travées tout comme la nef actuelle. À l'extérieur, chaque travée est marquée par la présence d'un contrefort au soubassement très saillant suivi de deux retraits avant un glacis sommital. Sur le chevet et le bras nord du transept, ces renforts s'élèvent jusqu'à la corniche et l'interrompent (cf. fig. 2). Sur la façade occidentale et les pignons du transept, les contreforts, d'angle, présentent une structure en équerre en prolongement des murs. Un escalier hors-œuvre est enfin ménagé en saillie du mur ouest du bras sud du transept.

5 Selon l'étude rapide menée par l'architecte en chef des Monuments historiques, P.A. Gatier, à la suite de l'effondrement d'une voûte en 2000, la principale campagne de construction (chevet et transept) daterait de la fin du XII ${ }^{\mathrm{e}}$ ou du début du XIII ${ }^{\mathrm{e}}$ siècle, sur $d^{\prime}$ '« anciennes fondations dont la date reste indéterminée $»^{3}$. Les contreforts du bras nord appartiendraient à une campagne de travaux postérieurs, avec un appareil homogène en grès ${ }^{4}$, la nef, ruinée au XIX ${ }^{e}$ siècle, ayant été reconstruite en 1894-18955. Ce phasage méritait d'être interrogé et précisé avant les nouvelles restaurations.

\section{Données archéologiques}

\subsection{Un édifice en négatif (état 1 , avant la fin du fin $\mathrm{XII}^{\mathrm{e}}$ siècle)}

6 La présence de sépultures recoupées par les fondations du chevet de l'église atteste l'existence d'une nécropole (sondage 5), peut-être associée à l'édifice antérieur pressenti par P.-A. Gatier. Le squelette 5011 a pu être inhumé entre la fin du $x^{\mathrm{e}}$ et la première moitié du XI ${ }^{\mathrm{e}}$ siècle (fig. 3$)^{6}$. 
Fig. 3 - Sépultures de l'état 1 recoupées par les fondations du chevet (cl. S. Paris et I. Richard).

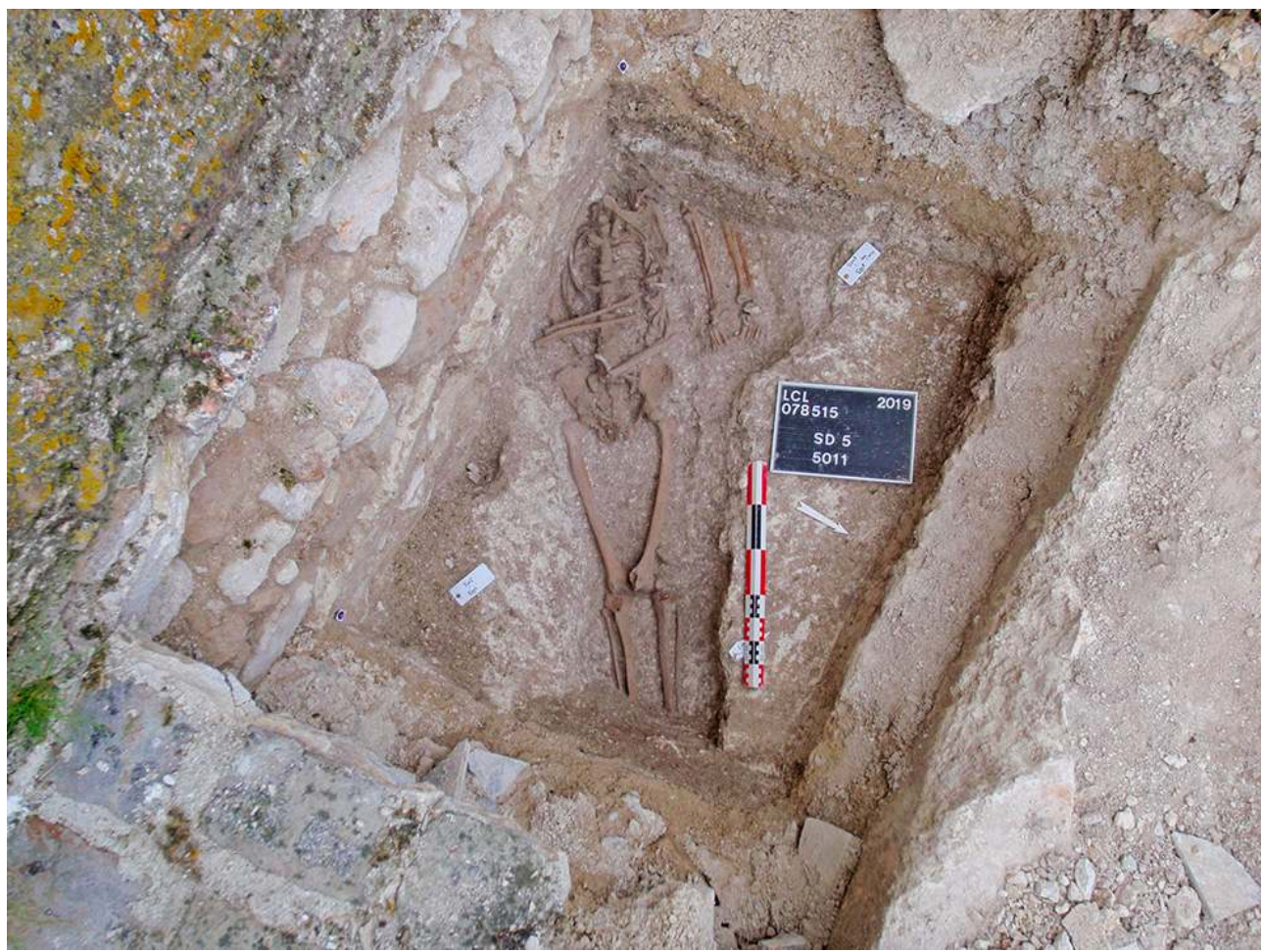

\subsection{L'édifice gothique (état 2 , fin $X I^{e}$-début $X I I^{\mathrm{e}}$ siècle)}

7 Ce deuxième état correspond à l'édification du chevet, de l'abside et des piliers de la croisée du transept.

\subsubsection{Le chevet}

8 Les fondations se caractérisent par des maçonneries soignées à double ou simple ressaut (fig. 4). 
Fig. 4 - Relevés des maçonneries au droit des sondages (cl. et DAO D. Duda et C. Roms).
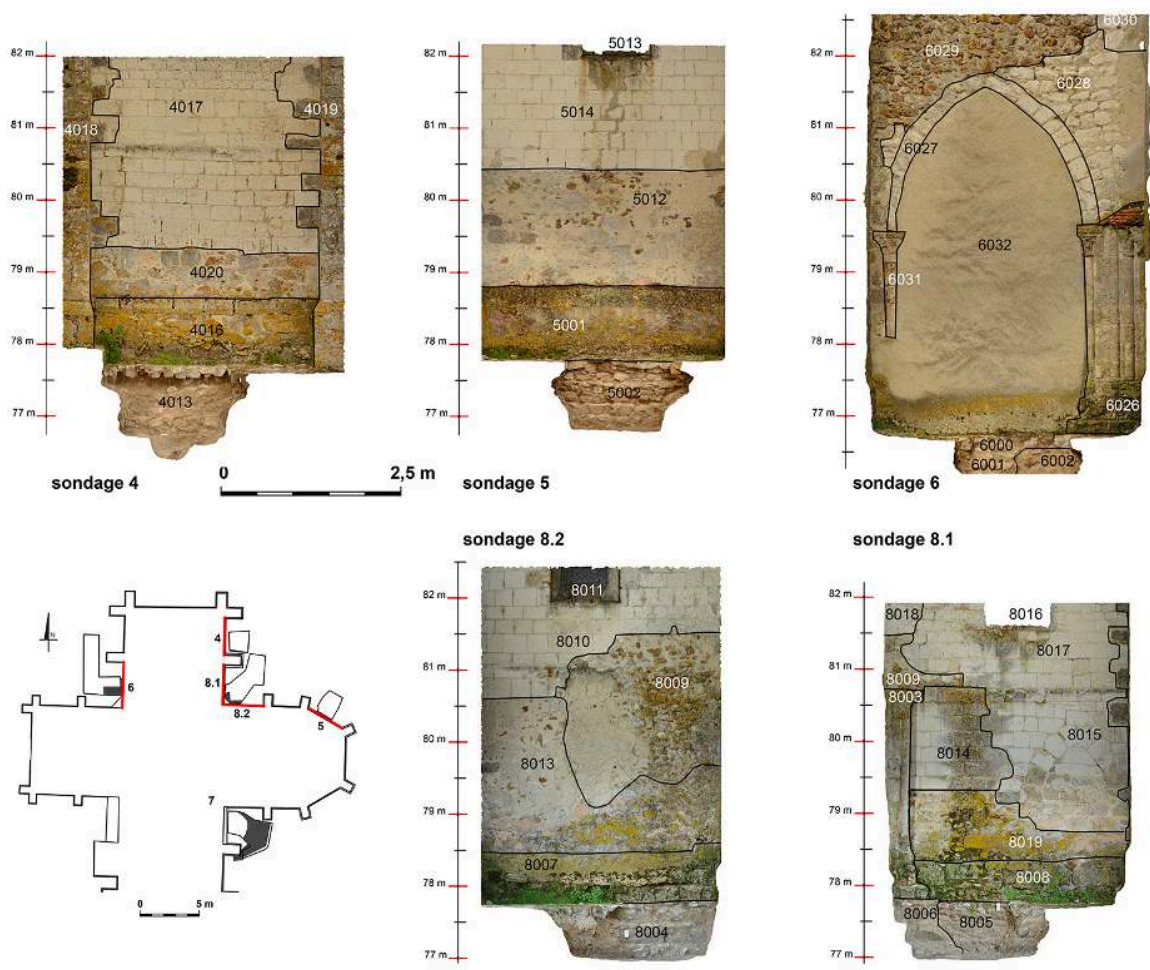

9 Côté nord, on note un premier débord, à la base de la fondation $(0,60 \mathrm{~m}$ sous le sol actuel), de $0,20 \mathrm{~m}$ à $0,25 \mathrm{~m}$ par rapport à l'aplomb du soubassement de l'élévation. La maçonnerie se poursuit jusqu'à la base de l'élévation avec un second ressaut de 0,15 m. Les assises inférieures de la maçonnerie sont réalisées en moellons de craie; dans la partie supérieure, ils sont en grès.

Côté sud, un unique ressaut de $0,10 \mathrm{~m}$ a été observé $0,50 \mathrm{~m}$ sous le niveau de pavé. Les matériaux mis en œuvre suivent la même organisation que dans les maçonneries précédentes.

11 Le pilier est fondé sur un massif - $0,73 \times 0,34 \mathrm{~m}$, pour la largeur maximale visible -, où seuls des moellons de craie sont employés. Le liant utilisé pour les fondations est un mortier maigre, terreux avec du sable fin.

Les élévations des parements extérieurs du chevet s'organisent en trois parties distinctes (cf. fig. 4, 1) :

- un soubassement de petits moellons de grès, haut de $0,75 \mathrm{~m}$, en saillie d'une dizaine de centimètres, repose sur les fondations. La transition avec la deuxième partie se fait au moyen d'un bandeau de pierres de taille en calcaire de moyen appareil (h. 0,30 m);

- la maçonnerie médiane, qui mêle moellons de grès et pierres de taille calcaires, se développe sur une hauteur de 1,60 m environ. Un mortier de chaux aux joints couvrant assure la liaison entre les blocs ;

- le parement supérieur est composé d'un petit appareil de craie aux assises régulières, assemblé au mortier de chaux - certains blocs présentent des traces de bretture. La maçonnerie s'achève par une corniche décorée d'une alternance de têtes humaines et de fleurs à quatre pétales. 
Cette corniche est interrompue par les six contreforts à profil assez plat scandant le chevet. Les pierres de taille les composant sont assemblées en carreaux et boutisses, assurant une liaison par chaînages latéraux avec les pans du chevet. La base des contreforts jusqu'en haut du deuxième retrait et les glacis sont réalisés en calcaire tandis que la partie supérieure est en craie, selon la partition déjà observée sur les murs.

Sept fenêtres à lancette s'intercalent entre les contreforts. Piédroits, alternant carreaux et boutisses, et appuis sont réalisés en pierre meulière, un calcaire siliceux très solide ; les claveaux des arcs brisés sont en craie plus tendre. Chaque fenêtre est surmontée d'un second arc brisé reposant sur deux têtes humaines et sculpté de fleurs à quatre pétales de même facture que celles de la corniche.

\subsubsection{L'absidiole sud}

Le sondage 7 a permis de retrouver les vestiges d'une abside déjà découverts à la fin des années 1960 (fig. 5).

Fig. 5 - Fondations de l'abside sud (cl. C. Roms).

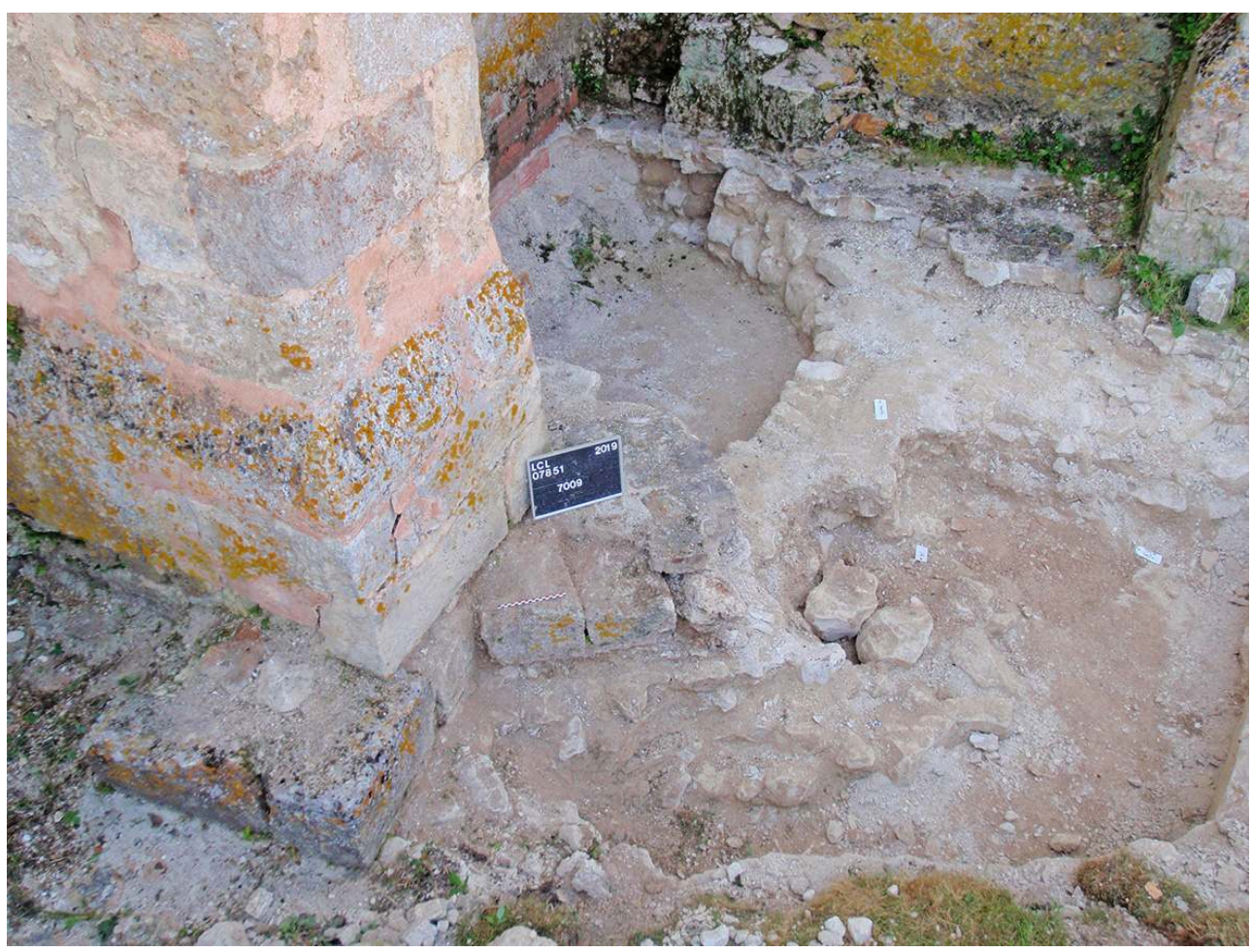

Cette absidiole semi-circulaire se développe sur une largeur intérieure de 2,50 m pour une profondeur de $1,50 \mathrm{~m}^{7}$. Épaisse d'au moins $1,90 \mathrm{~m}$, la fondation soignée offre un parement de moellons et une fourrure de blocs de craie liés au mortier de chaux. Elle s'appuie contre la fondation du chevet.

L'élévation est partiellement conservée malgré la récupération des pierres et l'installation de sépultures. On retrouve au sud, sous le contrefort, une assise de blocs de calcaire taillés. L'épaisseur du mur en élévation mesure 0,85 m (fig. 6). 
Fig. 6 - Élévation de l'absidiole sud arasée servant d'assise à un contrefort du bras du transept (cl. C. Roms).

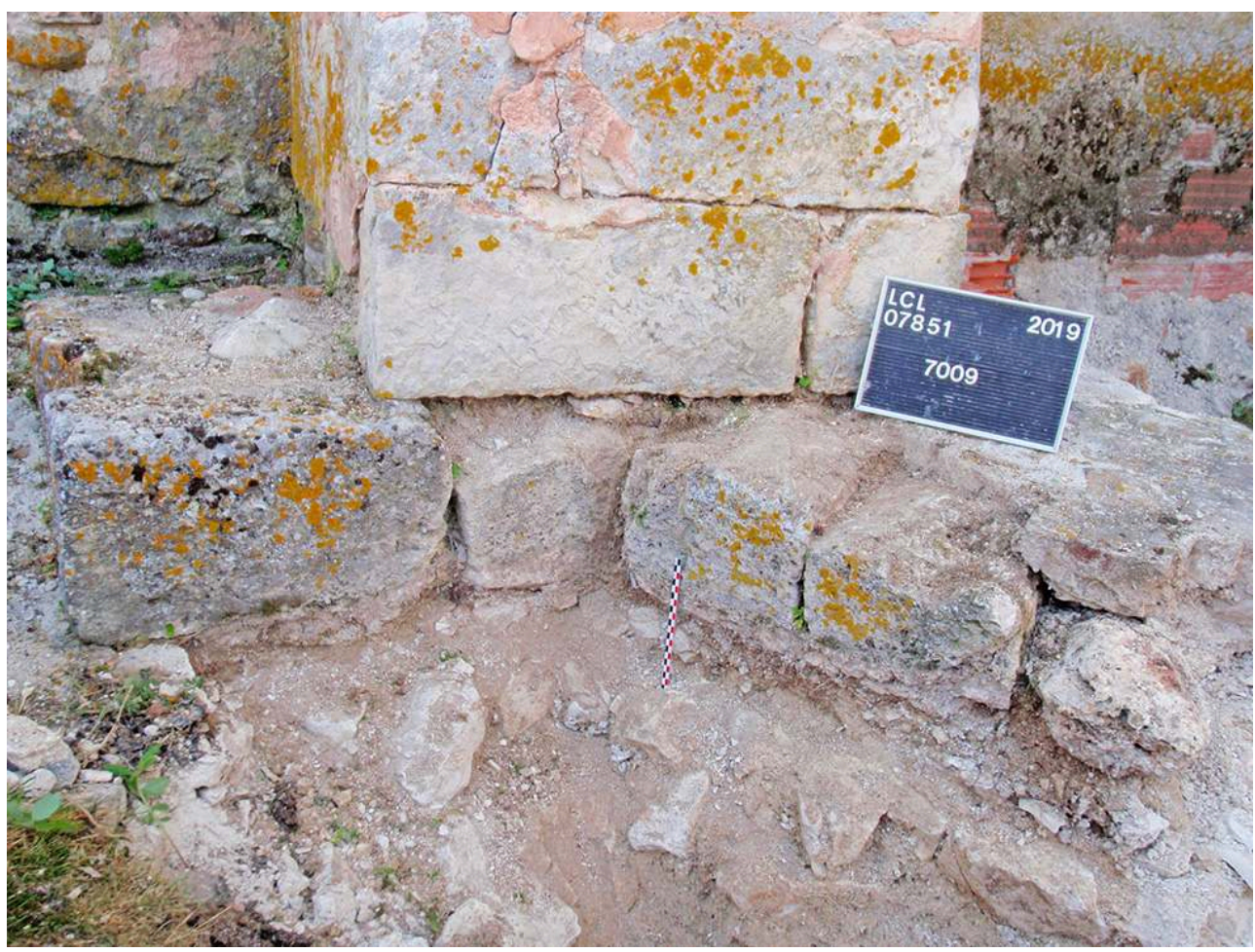

Dans l'église subsiste l'arc de tête muré de l'abside, un arc brisé en craie reposant sur des colonnettes en vis-à-vis ; les départs de sa voûte sont également conservés.

\subsection{3. Éléments des piliers nord de la croisée du transept}

Des éléments de massifs maçonnés correspondant aux piles de la croisée sont visibles aux angles du bras nord du transept avec le chevet et la nef. Leur présence sous les élévations actuelles indique que ces piles étaient situées originellement à l'intérieur d'un édifice plus vaste que celui qui a été reconstruit au XIXe siècle.

20 À l'est, au-dessus du sondage 8 , un fût de colonnette en meulière, surmonté d'un chapiteau à crochets végétaux, présente une base très fortement érodée reposant sur le massif de fondation gothique en grès (fig. 7). 
Fig. 7 - Base de pilier et colonnette engagée dans l'angle entre le chevet et le bras nord du transept (cl. C. Roms).

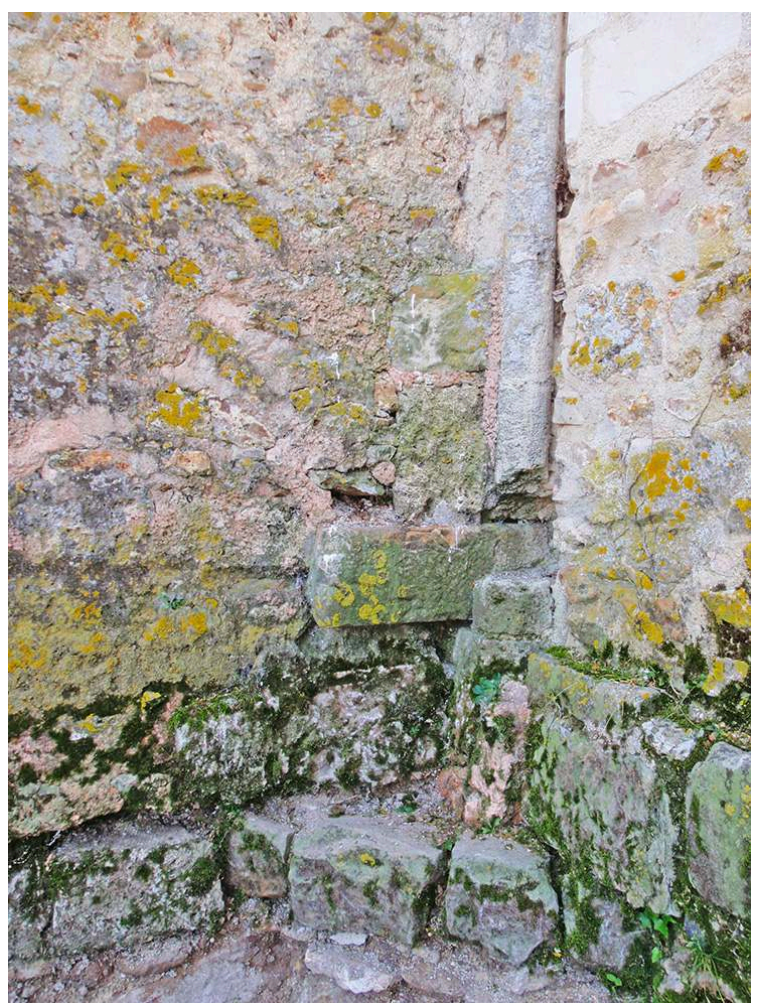

21 La présence de cette colonnette à l'extérieur ainsi que d'autres à l'intérieur, de même facture que celle de la baie ouvrant dans l'abside sud, laisse supposer la présence d'une seconde absidiole. Pourtant aucune trace n'a été observée dans la tranchée 8 . Il faut peut-être y voir un projet avorté.

Quelques assises conservées dans le transept suivent celles du chevet : il pourrait s'agir d'une maçonnerie de l'état 2, mais des observations plus précises auraient été nécessaires pour l'assurer.

23 À l'ouest, le sondage 6 a livré la suite du pilier fasciculé de la croisée (cf. fig. 4) : trois colonnettes surmontées d'un chapiteau à crochets végétaux et le départ de colonnes taillés dans du calcaire. Le pilier est fondé sur un massif de moellons de grès et silex pris dans un mortier de chaux très sableux avec à la base des moellons de craie. Cette fondation se développe sur 1,55 m vers l'ouest et disparaît sous la limite de fouille au $\operatorname{sud}(0,70 \mathrm{~m}$ visible).

Les colonnettes faisant pendant à celle que nous venons de décrire accueillent les retombées d'un arc brisé aux claveaux de craie (cf. fig. 4) ${ }^{8}$. À l'intérieur de l'édifice (fig. 8), l'arc repose également sur des paires de colonnettes surmontées de chapiteaux en craie dont la corbeille présente les mêmes crochets végétaux (feuilles et fleurs).

Fig. 8 - Arc brisé à l'intérieur de l'église (cl. C. Roms).

Le parement est partiellement conservé au-dessus de l'arc brisé. Il s'agit comme au chevet d'un petit appareil de craie. On observe également dans cette pile deux autres colonnettes (cf. fig. 4), côté nef, indiquant l'existence d'une voûte sur croisée d'ogives et d'un autre arc oblitéré par la nef actuelle. En partie haute, un arrachement laisse apparaître des moellons de craie témoignant d'un départ de voûte (fig. 9). 
Fig. 9 - Arrachement dans la partie supérieure du bras nord du transept, côté ouest (cl. C. Roms).

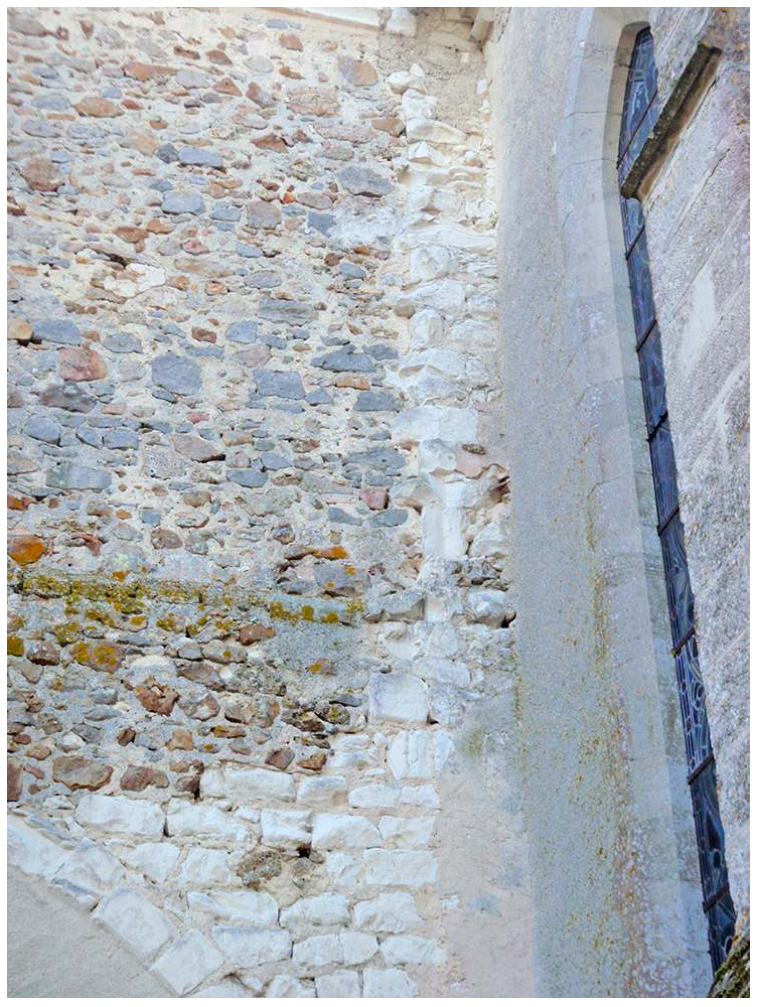

Tous ces éléments conjugués suggèrent l'existence d'un collatéral, mais aucune trace de mur n'a été observée dans la tranchée 6.

\subsection{4. Éléments de datations}

La datation de cet état 2 se fonde sur la chronologie communément admise, de la fin du XII ${ }^{\mathrm{e}}$-début du XIII ${ }^{\mathrm{e}}$ siècle, ce que n'exclut pas la datation de la sépulture 5001.

Des rapprochements stylistiques peuvent logiquement se faire entre les chapiteaux des piles 6031 et 6026 (cf. fig. 4) et ceux des baies des bras du transept, des autres piles de la croisée et du chœur (fig. 10a). On note également une proximité avec les chapiteaux du porche du XII ${ }^{e}$ siècle de l'église Saint-Hilaire de Saint-Thierry (Marne, fig. 10b) ${ }^{9}$ ou avec ceux du portail occidental de Saint-Médard d'Any-Martin-Rieux (Aisne, fig. 10c) datés de la fin $\mathrm{XII}^{\mathrm{e}}$-XIII ${ }^{\mathrm{e}}$ siècle $^{10}$. 
Fig. 10 - Chapiteaux à crochets végétaux.

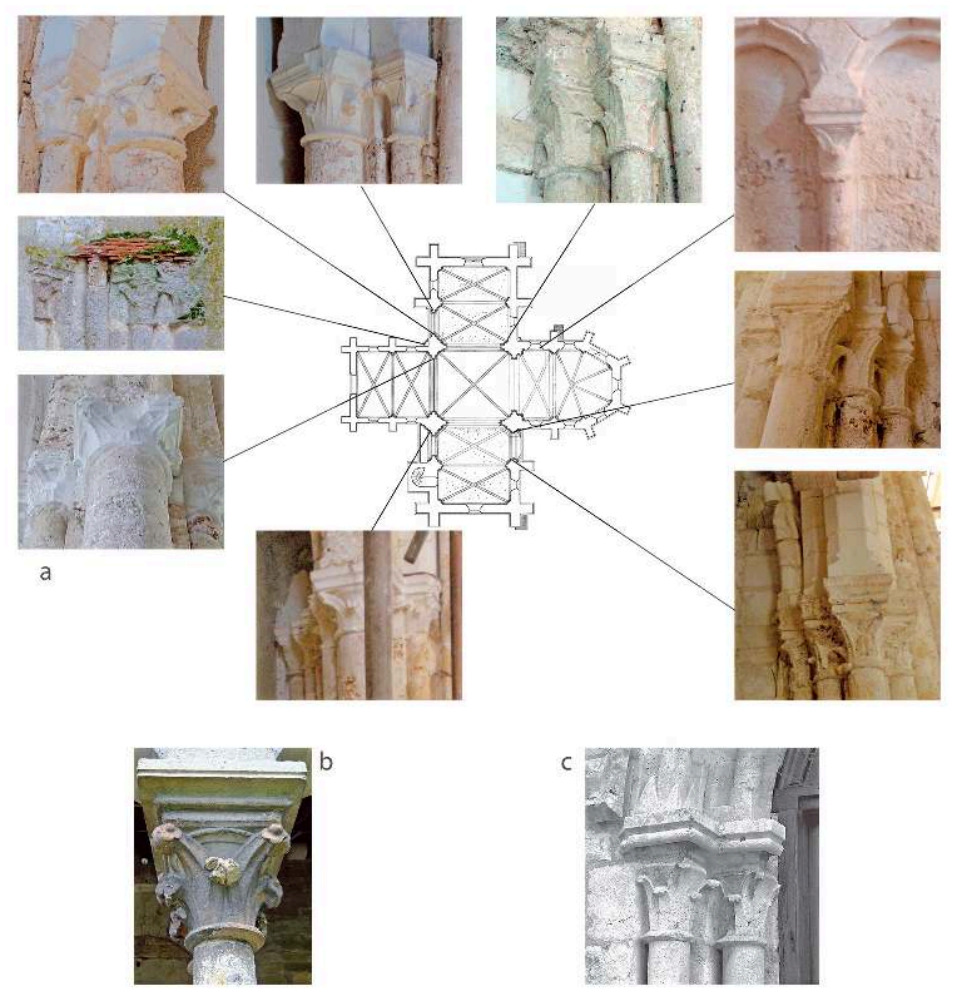

a. église Saint-Pierre (cl. C. Roms) ; b. porche (x॥ e siècle) de Saint-Hilaire de Saint-Thierry (cl. F. Mulot, Inventaire général Grand-Est) ; c. portail occidental (fın x॥I ${ }^{\mathrm{e}} \mathrm{xIII}{ }^{\mathrm{e}}$ siècle) de Saint-Médard d'Any-MartinRieux (cl. T. Lefébure, Inventaire général Hauts-de-France).

\subsection{Bras sud du transept (état 3 , avant la fin du XIVe-début Xve siècle)}

La réalisation $\mathrm{du}$ bras méridional du transept intervient postérieurement à la démolition de l'absidiole sud ; un des contreforts prend en effet appui sur un de ceux de l'abside.

31 Les élévations du mur oriental de cette aile sud se développent verticalement en trois parties. À la base, un soubassement en moellons de grès, en grande partie masqués par un mortier de chaux, est surmonté d'un bandeau de blocs de grès. La zone médiane de l'élévation, en moellons de grès, occupe la moitié de la hauteur du mur. Puis vient un petit appareil de craie aux assises régulières, lié avec un mortier de chaux beige. Au droit du sondage 7 , au-dessus du bouchage $\mathrm{du} \mathrm{xx}^{\mathrm{e}}$ siècle, on note que le mur du transept s'appuie contre le chevet.

Un contrefort se trouve à l'extrémité du bras et un second dans la partie médiane. Ils sont constitués à leur base de moellons et blocs de grès et, en élévation, de blocs de meulière liés avec un mortier de chaux à sable grossier. Comme au chevet, les chaînages latéraux des organes de contrebutement avec le parement du mur sont réalisés en carreaux et boutisses. Assez plats, ces contreforts rectangulaires à ressauts, qui s'élèvent jusqu'à la corniche qu'ils interrompent, sont contemporains du parement et de la corniche. 

sépulture datée d'entre 1320 et $1440^{11}$ - avec une probabilité à $76 \%$ entre 1390 et 1440 . On peut donc envisager la construction du transept sud au plus tôt à la fin du XIII ${ }^{\mathrm{e}}$ siècle.

\subsection{Le bras nord du transept (état $4, x V l^{e}$ siècle)}

\subsubsection{Fondations}

Dans le sondage 4, le massif de fondation présente deux ressauts de $0,10 \mathrm{~m}$ à $0,25 \mathrm{~m}$ sous le niveau de sol actuel, en moellons de craie, et un second, de $0,25 \mathrm{~m}$ à $0,55 \mathrm{~m}$ du sol, composé d'une assise unique de blocs de grès (cf. fig. 4). La base visible de la fondation est réalisée en moellons de craie (deux assises). Un mortier de chaux sableux beige assure la liaison des blocs mis en œuvre. Si le second ressaut n'est pas présent dans la fondation du contrefort 4018 , on note la même alternance de matériaux et un débord d'une vingtaine de centimètres par rapport à la base du contrefort à une profondeur de 0,30 m. Les assises de 4013 et 4014 se suivent ; tout laisse penser qu'elles correspondent à la même phase de construction.

Dans la tranchée 8 (cf. fig. 4), la fondation est seulement composée de grès pour les dix assises visibles. Cette fondation s'appuie contre la maçonnerie de l'état 2.

\subsubsection{Les élévations extérieures}

On note des différences dans les maçonneries des murs est (sondages 4 et 8) et nord avec le mur ouest (sondage 6, cf. infra). À l'est, l'élévation présente une construction relativement homogène avec un soubassement de grès en débord, surmonté d'un bandeau de grès (chanfreiné pour 4016) assurant la transition avec une maçonnerie de moellons de grès associés à de la meulière (cf. fig. 4).

Le reste de l'élévation est constitué d'un petit appareil de craie aux assises régulières dont les hauteurs s'amoindrissent à partir de $3,80 \mathrm{~m}$; ceci semble résulter d'un changement d'approvisionnement. On l'observe également sur la face sud de l'aile du transept.

Une fenêtre en plein cintre, contemporaine du parement 8017, perce le mur oriental du bras nord du transept. Au-dessous, l'arc de décharge (cf. fig. 4) correspond à un arc observé à l'intérieur et qui surmonte un lavabo liturgique - témoignant de la présence d'un autel dans cette aile. La base de cet arc brisé est construite en pierre calcaire tandis que le reste des claveaux est en craie.

\subsection{3. Éléments de datation}

La fenêtre du pignon nord, dont les blocs d'encadrement semblent suivre les assises du parement, trouve une comparaison à l'église de Buxières-lès-Villiers (Haute-Marne) du $\mathrm{XVI}^{\mathrm{e}}$ siècle, avec une baie certes moins élancée (fig. 11 et 12$)^{12}$. 
Fig. 11 - Fenêtre du xvle siècle du pignon nord du transept (cl. C. Roms).

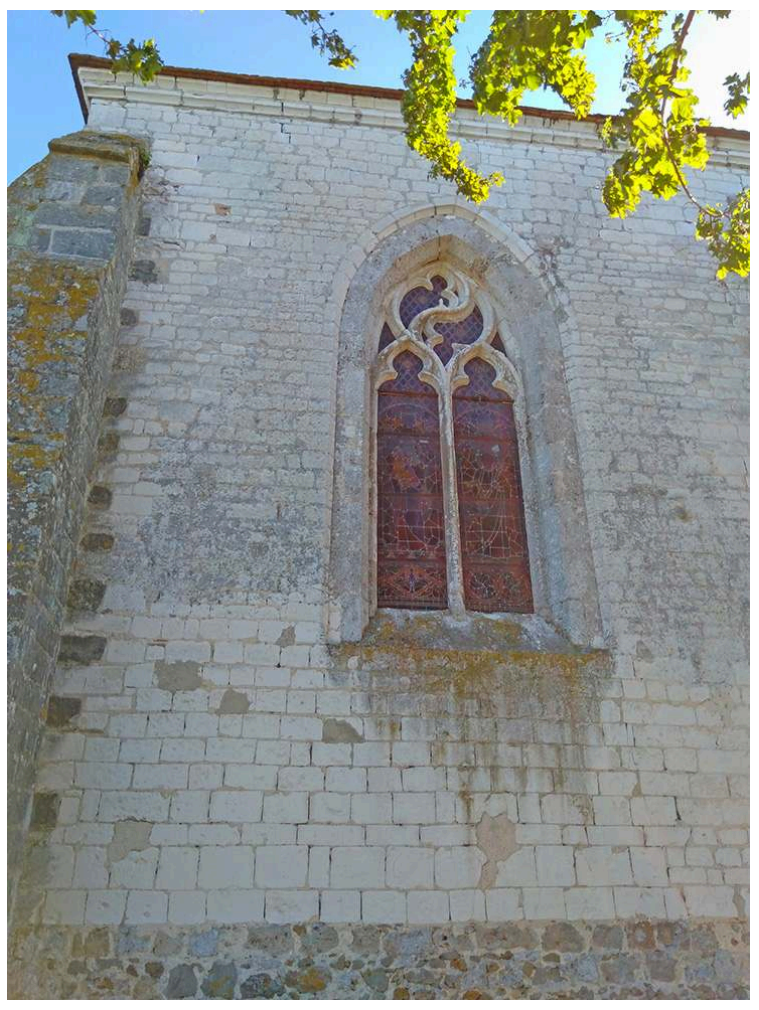

Fig. 12 - Fenêtre du Xvle siècle de l'église de Buxières-lès-Villiers en Haute-Marne (cl. J. Marasi, Inventaire général Grand-Est).

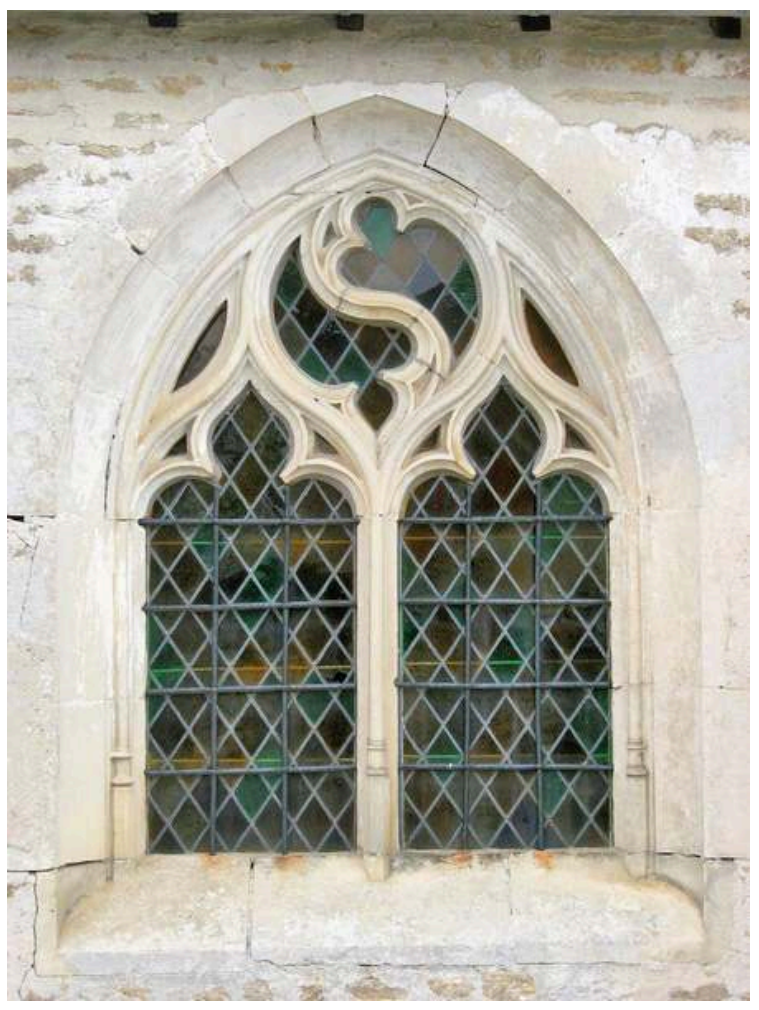

40 La datation offerte par cette proximité stylistique concorde avec celle de l'analyse des bois de constructions par W. Tegel (DendroNet) qui avance la date de 1504. 
L'achèvement de la construction du bras septentrional du transept coïnciderait en effet avec la mise en place d'une nouvelle charpente sur le transept et le chœur.

\subsection{La question des contreforts du bras nord (état 5)}

41 Les contreforts du bras nord du transept ont toujours été réputés postérieurs au parement. L'agencement des contreforts et du parement pose question (cf. fig. 4). Si leurs fondations paraissent synchrones dans la tranchée 4, on perçoit dans les élévations des variations d'assisage qui pourraient être liées à un mauvais réglage. Néanmoins, en élévation, les contreforts semblent fonctionner avec le parement 6029, côté ouest. Or cette maçonnerie de blocs et moellons de grès, liés avec un mortier de sable grossier, diffère fortement de celle observée au sud et à l'est, avec ses contreforts de même facture - pierres de taille en grès avec chaînage en carreaux et boutisses. Si les contreforts sont postérieurs, peu d'éléments attesteraient de la présence de renforts contemporains du parement de l'état 4 .

\subsection{Un état de la nef antérieur à 1871 (état 6)}

L'un des objectifs de la tranchée 1 était de détecter la présence d'éléments de la nef médiévale. Malheureusement, les maçonneries découvertes sont probablement à rattacher à un état tardif, figuré sur un dessin de 1871 représentant une nef plus basse que la nef actuelle (fig. 13) ${ }^{13}$, construite en 1894 (état 7).

Fig. 13 - Dessin de l'église par É. Gastebois (1871), Reims, B. M. 73-003, CXIII 2901.

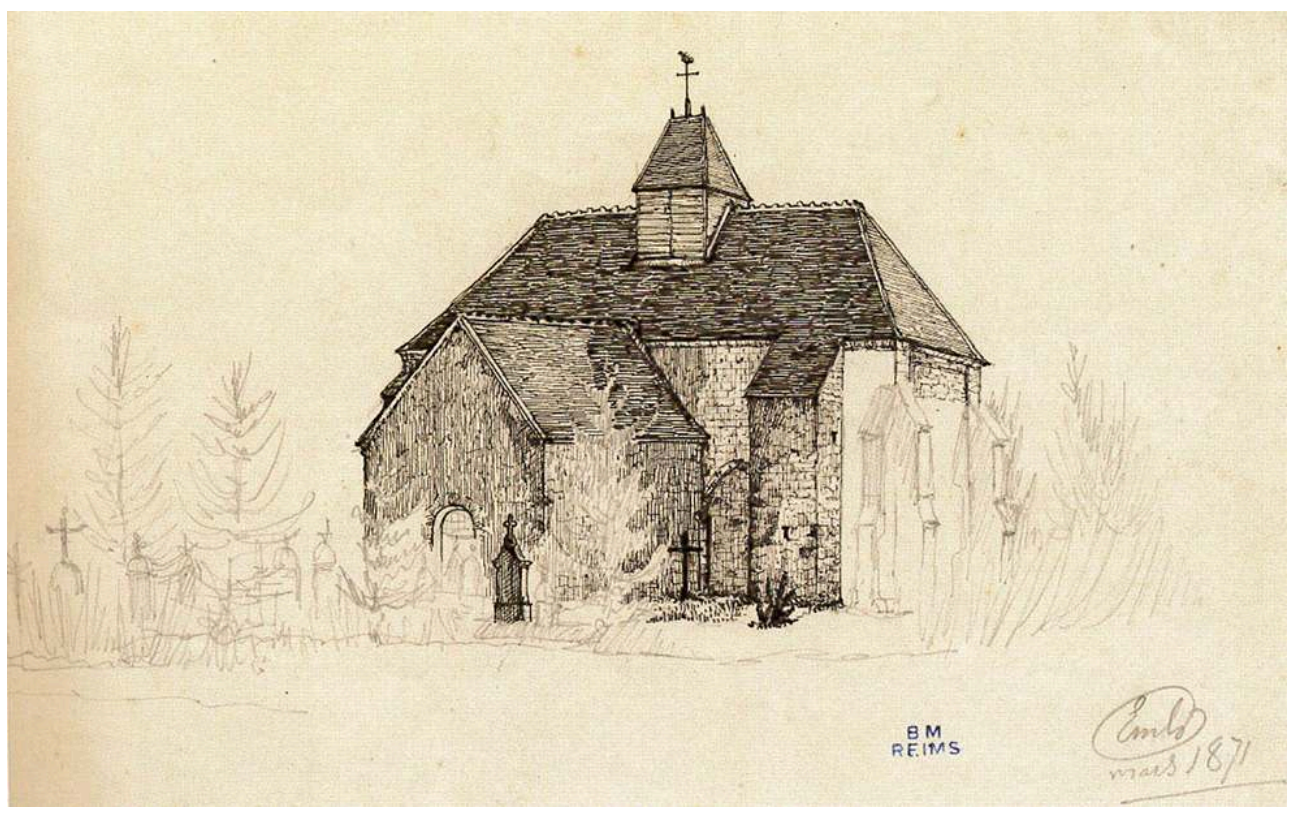

Une première maçonnerie orientée nord-sud a été mise au jour en limite de tranchée. Elle a été observée sur une longueur de $5 \mathrm{~m}$ avant de disparaitre dans la coupe. Elle n'a pas été vue sur toute son épaisseur. Ce mur est constitué de moellons de calcaire, de grès et de craie liés avec un mortier sableux (fig. 14). 
Fig. 14 - Mur pignon de la nef de l'état 6 (cl. C. Roms).

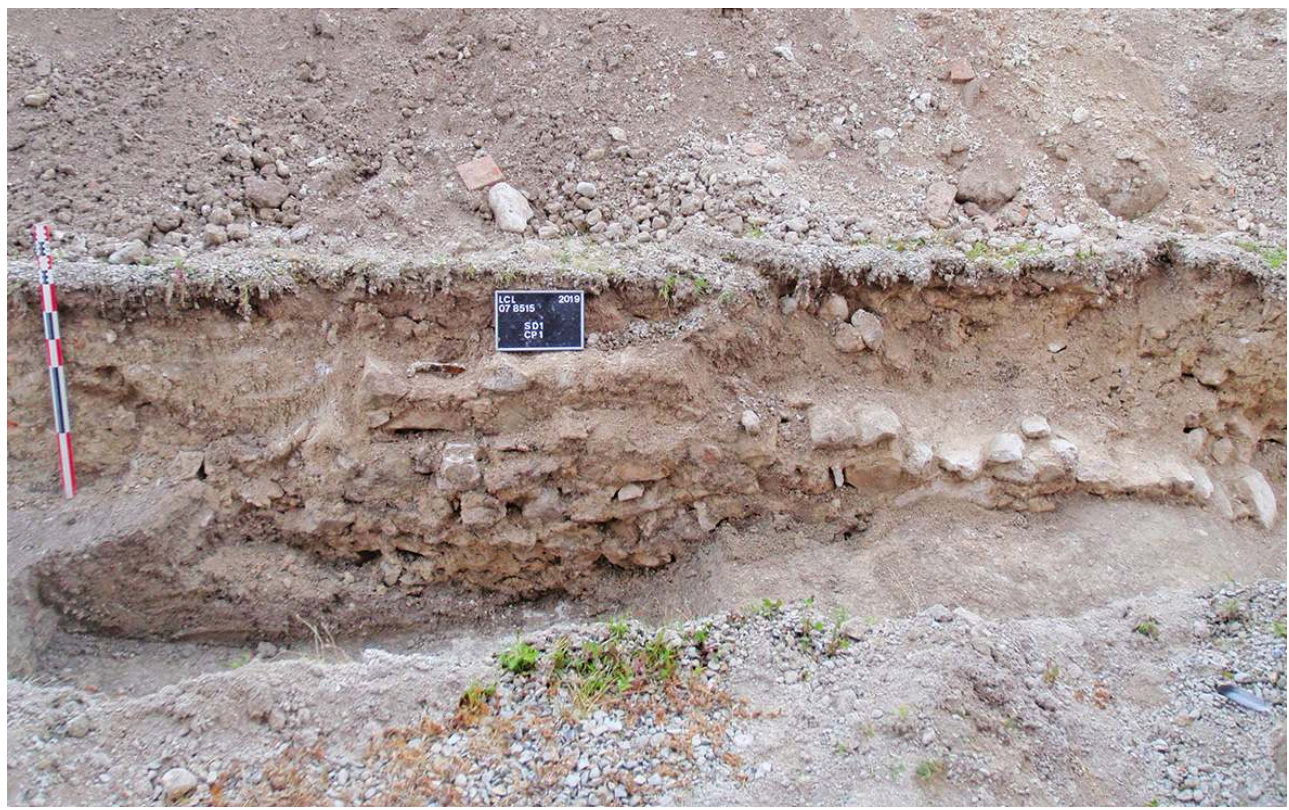

44 Le mur qui fait retour au nord a été en grande partie récupéré ; il se dirige vers l'est dans l'axe de la nef actuelle. On n'a pas observé de retour au sud et l'implantation du mur gouttereau n'a pas pu être fixée, ni la largeur de cette nef d'époque moderne.

\subsection{Les matériaux lithiques mis en œuvre}

Trois types des pierres ont été observés tant dans les fondations que dans les élévations. Les déterminations ont été faites in situ et comparées avec la notice de la carte géologique $^{14}$, sans analyse pétrographique. La disponibilité et la proximité quasi immédiate de ces matériaux - à moins de $15 \mathrm{~km}$ - expliquent les différents choix (fig. 15). 
Fig. 15 - Carrières ayant pu alimenter les chantiers de l'église (DAO C. Roms, sur fond carte géologique au $1 / 50000^{\mathrm{e}}$, BRGM).

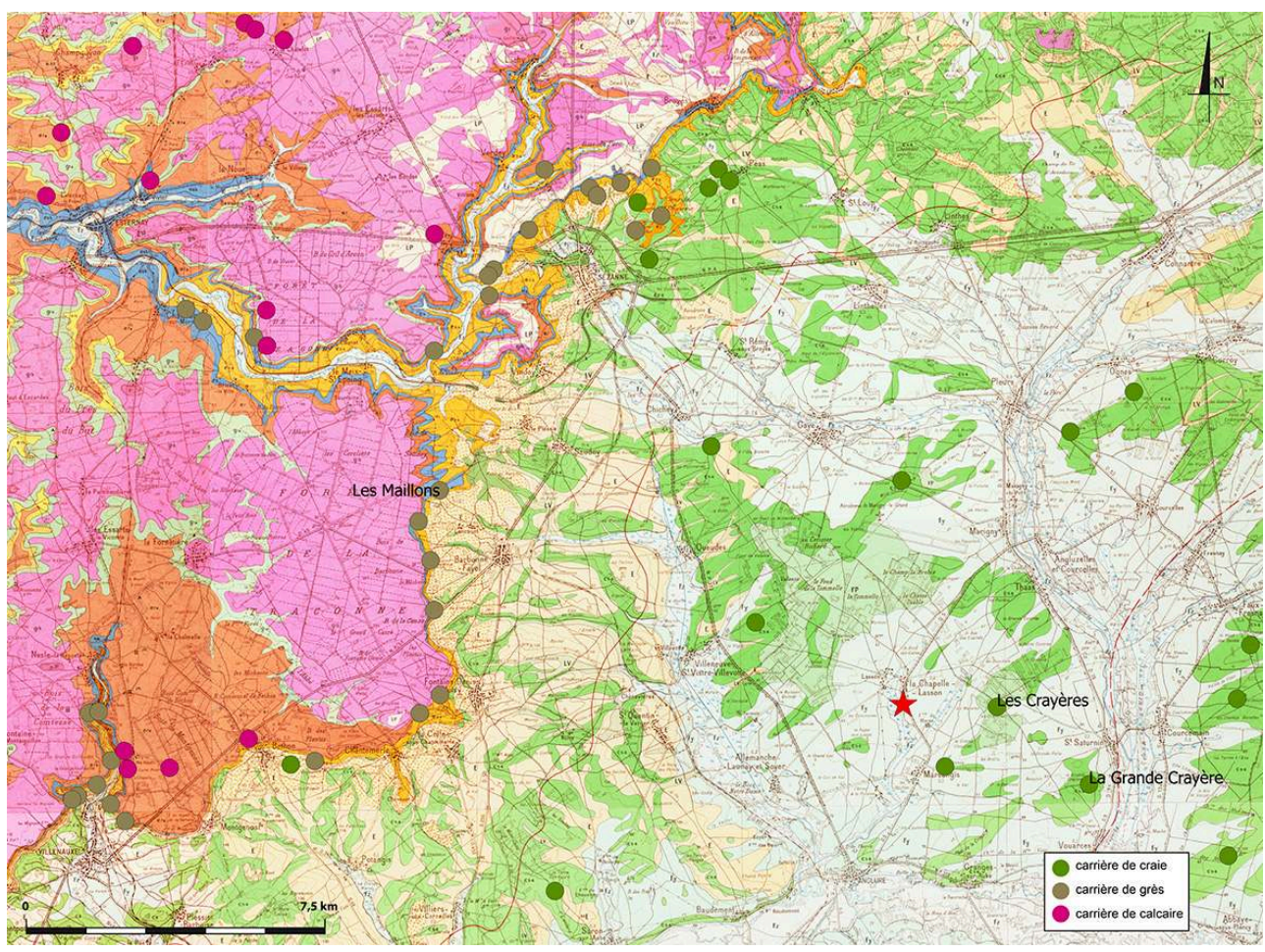

\subsubsection{La craie}

La craie (Campanien - Santonien, c5-6) occupe la plus grande partie de la feuille Sézanne; elle constitue toute la région à l'est et au sud de la falaise tertiaire. Une carrière comblée figure sur la carte géologique à $4,25 \mathrm{~km}$ au nord-est de La ChapelleLasson - commune de Villeneuve-Saint-Vistre-Villevotte. À Marsangis, on en trouve une autre et un lieu-dit Les Crayères, tous deux à environ $2 \mathrm{~km}$ à l'est et au sud-est de notre église. L'Atlas de Trudaine représente une carrière à une distance de $8 \mathrm{~km}$. La craie, abondante, facile d'accès et aisément taillable, constitue donc un matériau privilégié pour les fondations, les élévations et la réalisation des arcs et des voûtes de l'église.

\subsubsection{Le grès}

47 Le grès de l'Yprésien (e3-4) est d'aspect fin, dur, à cassure nette, lustrée, de couleur gris bleuté. Il peut être exploité en carrières: la carte géologique en figure plusieurs, abandonnées et comblées, d'où du grès a pu être extrait. L'une d'entre elles se trouve au lieu-dit Les Maillons sur la commune de Barbonne-Fayel, à $13 \mathrm{~km}$ de notre église. Les pierres mises en œuvre peuvent également provenir de blocs de grande taille observés le long de la falaise et parfois même à d'assez grandes distances de celle-ci. Le grès a été employé en fondations et en élévation, parfois associé à du calcaire et de la craie, à toutes les périodes.

\subsubsection{Le calcaire de type « meulière »}

La pierre meulière a été observée dans les maçonneries de l'église. En l'absence d'analyses pétrographiques, nous préférons rester prudents et envisager qu'il puisse 
s'agir soit de meulière de Brie (Sannoisien supérieur, g1b), soit de calcaire de Champigny (Ludien, e7). Les premiers affleurements sont distants d'une douzaine de kilomètres à l'ouest de la Chapelle-Lasson. Aux $\mathrm{XII}^{\mathrm{e}}$-XIII ${ }^{\mathrm{e}}$ siècles, ce matériau est mis en œuvre sous forme de pierre de taille dans les contreforts (glacis, soubassements) du chevet, dans les encadrements des baies du chevet (piédroits, appuis), les piliers et les fûts des colonnettes. Il marque également la limite entre le premier et le second soubassement du chevet dans lequel il est également présent sous forme de moellons.

\section{Le cimetière : données topographiques}

À l'exception de la tranchée 2, toutes les autres ont révélé la présence de sépultures 29 identifiées ou supposées, dont 11 fouillées - avec des densités différentes (cf. fig. 2). Tous les individus ont été inhumés selon les rites chrétiens: tête à l'ouest, sans mobilier d'accompagnement - les tessons retrouvés dans le comblement des sépultures sont en position résiduelle.

Le mur oriental du bras nord du transept (cf. fig. 4 et 16) porte de nombreux graffitis : quelques prénoms (CONSTAN, otis), un patronyme (GALLOM) et de nombreuses croix latines surmontant un triangle (calvaires). Autant d'éléments pour indiquer la présence de sépultures relevées ou pour lesquelles il n'existait aucune matérialisation de surface.

Fig. 16 - Graffitis à la base du mur 4017 (cl. D. Duda).

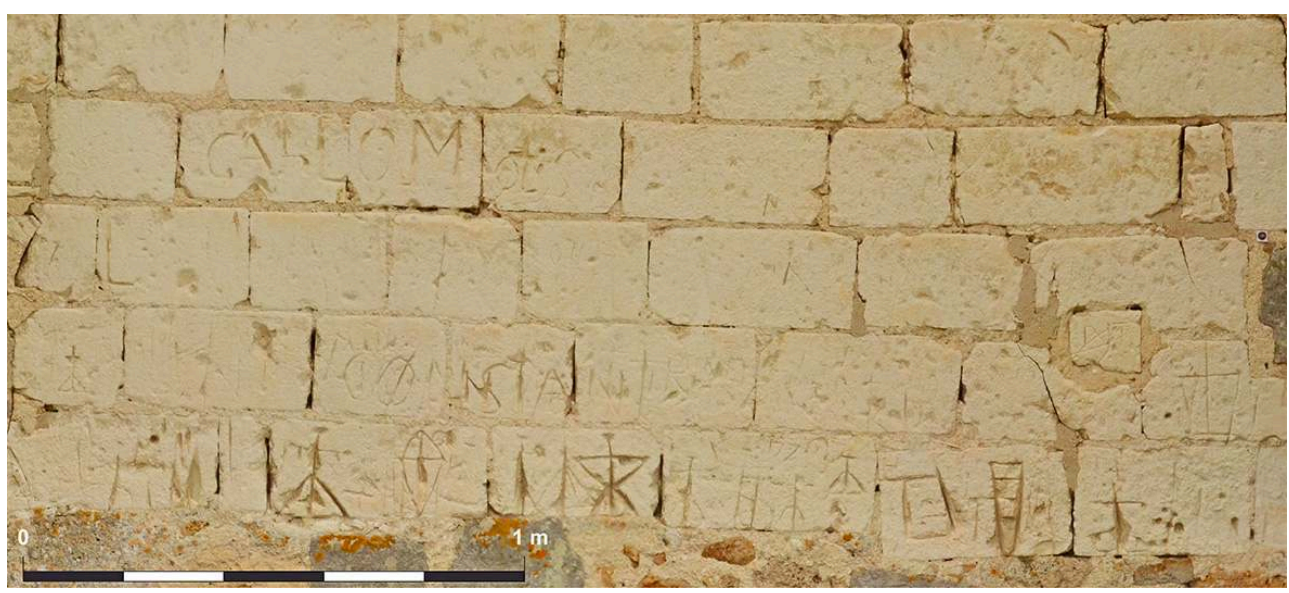

\section{Conclusion synthétique}

\subsection{Quelle origine pour cette église?}

51 Érudits et historiens attribuent une origine templière ou hospitalière à l'église SaintPierre, sans indiquer leurs sources. Pour M. Salle, «l'église [...] paraît être la chapelle d'une maison de Templiers dont on a vu les ruines $»^{15}$, représentées sur un croquis par P. Royer à l'ouest de l'église ${ }^{16}$. C. Lalore indique qu'il s'agit :

«d'abord d'un prieuré-hôpital, puis prieuré-cure de l'ordre de Saint-Jean de Jérusalem ou de Malte, à la présentation du grand prieur de France, ou du commandeur du Temple de Paris. [...] La Chapelle-Lasson était autrefois un hôpital duquel relevait l'hôpital de Rosnay et quand l'évêque visitait la Chapelle-Lasson il 
prélevait la redevance d'un florin de Florence à cause de l'hôpital de Rosnay, qui se

trouvait exempt par cette composition ${ }^{17}$.»

La documentation historique consultable dans le cadre de cette opération courte de diagnostic étant presque inexistante, il est difficile d'affirmer ou d'infirmer ces hypothèses. De fondation templière ou hospitalière, l'église devait s'inscrire dans un ensemble de bâtiments : habitation principale, résidence d'un commandeur, logis pour les frères, hospice ou hôpital, bâtiments agricoles... ${ }^{18}$. Ces origines supposées ne concernent que l'église de la fin du XII ${ }^{\mathrm{e}}$-début du XIII ${ }^{\mathrm{e}}$ siècle (état 2). Rien n'est en revanche connu sur un édifice antérieur (état 1) autour duquel se serait développée une nécropole ainsi qu'en témoignent trois sépultures, dont deux d'enfants, antérieures au milieu du XI ${ }^{\mathrm{e}}$ siècle.

\subsection{L'église de l'état 2 : un projet avorté ?}

L'un des objectifs du diagnostic était de remettre au jour les fondations de l'abside sud et de vérifier l'existence supposée d'une seconde absidiole au nord. Celle-ci n'a pu être mise en évidence ; seules une baie bouchée et des colonnettes attestent d'une ouverture donnant autrefois dans l'aile septentrionale de l'actuel transept. Le sondage 6, à l'ouest du bras nord du transept aurait pu démontrer l'existence du mur gouttereau d'un bascôté ; malheureusement aucune trace archéologique n'en a été détectée.

Face à plusieurs ouvertures désormais obturées très soigneusement, il convient d'envisager une église restée inachevée, dont le plan initial intégrait un chevet à pans coupés, encadré de part et d'autre par les absidioles des bras du transept et une nef à trois vaisseaux, les bas-côtés étant moins hauts que le reste de l'édifice. Le projet d'origine a pu ne pas être mené à terme, nef et abside nord n'ayant jamais été construites (fig. 17). 
Fig. 17 - Proposition d'évolution et phasage de l'église (DAO C. Roms, fond de plans et élévations P.-A. Gatier).
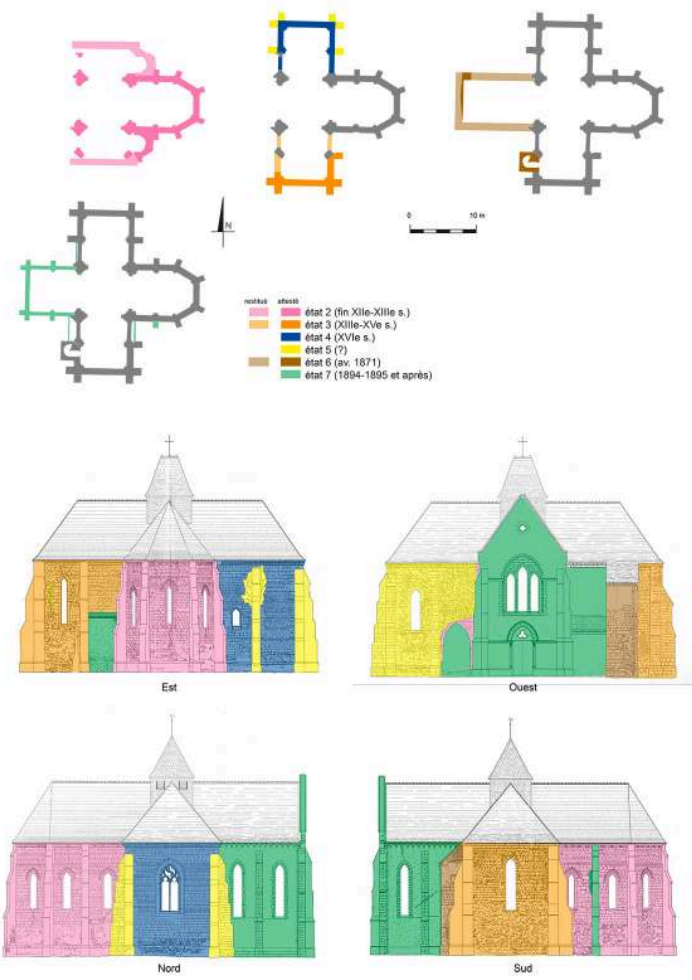

Les saignées creusées dans les piliers situés à la jonction entre la nef actuelle et la croisée du transept indiquent l'installation d'une cloison provisoire (en bois?). Il n'est pas possible de déterminer la période de réalisation de ses saignées : peut-être après l'abandon du projet d'origine et assurément avant la pose des carreaux de ciment constituant le dallage actuel (fig. 18). 
Fig. 18 - Base d'un pilier de la croisée de transept retaillé pour accueillir une cloison avant la mise en place des carreaux de ciment (cl. C. Roms).

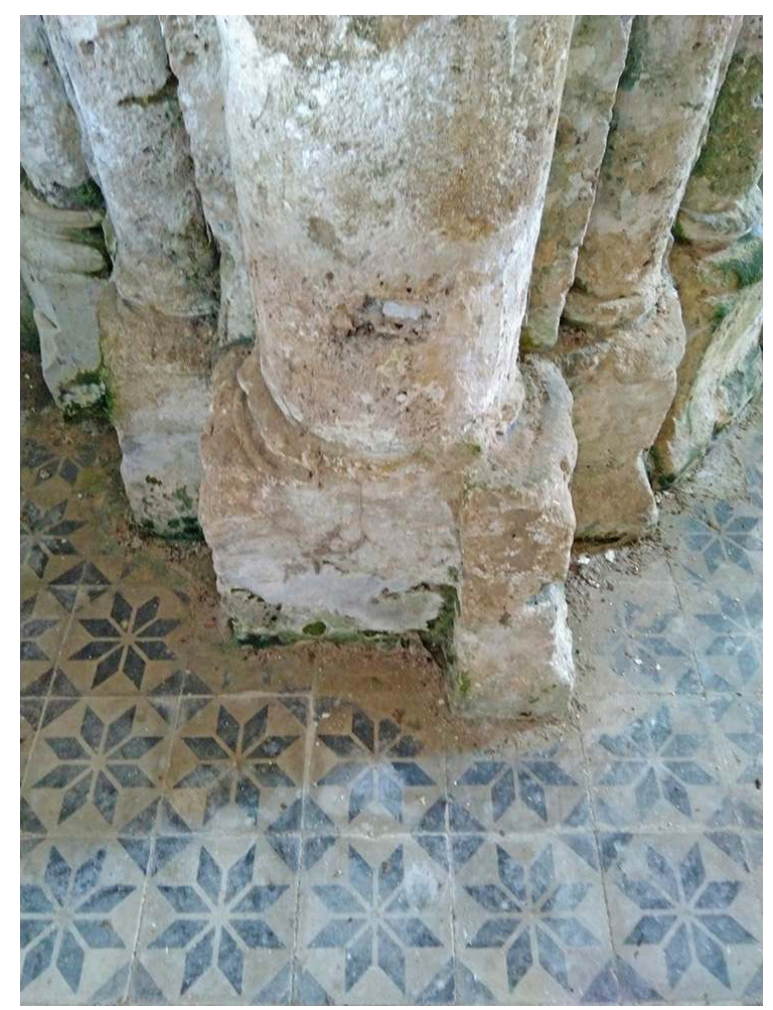

56 Si la construction de l'édifice de l'état 2 est bien d'origine templière, il contrasterait fortement dans sa facture, son ambition architecturale et ses dimensions avec les chapelles de l'Ordre de cette région, généralement à nef unique et à chevet plat, datées de la transition des XII $^{\mathrm{e}}$-XIII ${ }^{\mathrm{e}}$ siècles, comme celles de Fresnoy, d'Avalleur ou de Coulommiers (fig. 19). 
Fig. 19 - Chapelle de Fresnoy, fin du XII ${ }^{\mathrm{e}}$ siècle (cl. V. Marchaisseau).

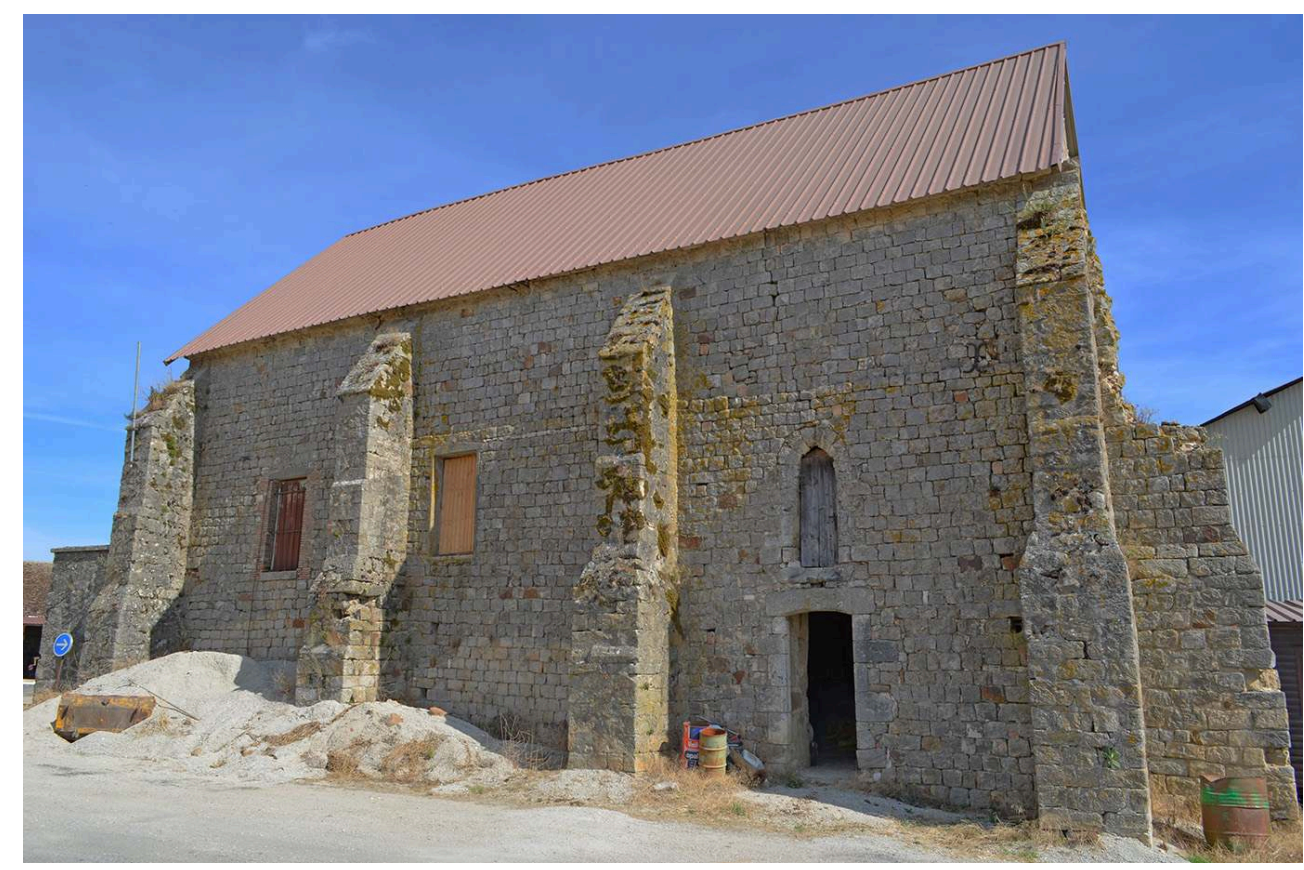

\subsection{Les bras du transept, des modifications du milieu et de la fin du Moyen Âge (états 3 à 5)}

La construction des ailes du transept s'est faite en deux temps (cf. fig. 17). On peut situer la réalisation du bras sud après la destruction de l'abside méridionale, les maçonneries de cette dernière servant pour partie d'assises à la nouvelle construction, intervenue au plus tôt avant la fin du XIV e siècle - datation induite par une sépulture de la première moitié de ce siècle (voir supra). Le second bras semble quant à lui dater du $\mathrm{XVI}^{\mathrm{e}}$ siècle, comme en témoigne la fenêtre gothique flamboyante de son pignon, concomitamment au remaniement de la charpente en 1504. La question d'une éventuelle reprise des contreforts (état 5) reste ouverte. Pour cette période aucun élément n'atteste la présence d'une nef.

\subsection{Enfin une nef (états 6 et 7 )!}

Deux maçonneries, pour partie récupérées, attestent enfin de l'existence d'une nef sans qu'il ne soit pour autant possible d'en dater la construction (état 6, avant 1871). La fin du XIX siècle voit la reconstruction de la nef et son raccourcissement qui aboutit au plan actuel en croix grecque (état 7, 1894-1895, cf. fig. 17).

Reçu : 6 septembre 2020 - Accepté : 25 novembre 2020 


\section{NOTES}

1. L'église a été classée au titre des Monuments historiques le 11 novembre 1972 [https:// www.pop.culture.gouv.fr/notice/merimee/PA00078657].

2. La maîtrise d'œuvre de ces travaux mandatés par la DRAC et la petite commune de La ChapelleLasson a été confiée à Florent Basset, architecte du patrimoine (Socrea, Compiègne).

3. P.-A. GATIER, Marne. Chapelle-Lasson. Église. Diagnostic du clos et couvert, Paris, 2003, p. 7 ; J.-

M. PÉROUSE DE MONTClos (dir.), Champagne-Ardenne, Paris, 1995, p. 143.

4. P.-A. GATIER, Marne. Chapelle-Lasson..., ibid., p. 8.

5. P.-A. GATIER, Marne. Chapelle-Lasson..., ibid.

6. Calibré à deux sigmas entre 968 et 1147 , probabilité de $90,5 \%$ entre 968 et 1046 (Beta Analytic-539163).

7. Mesures prises au niveau des fondations les élévations n'étant pas suffisamment conservées.

8. Le décor des chapiteaux est similaire à celui observé sur ceux du bras sud du transept.

9. Voir le dossier de l'Inventaire, en ligne [http://inventaire-patrimoine.cr-champagneardenne.fr/dossier/eglise-paroissiale-saint-hilaire-de-saint-thierry/722e0757-6722-4a26-a5a1-

b99b71340abc].

10. Voir le dossier de l'Inventaire, en ligne [https://inventaire.hautsdefrance.fr/dossier/egliseparoissiale-fortifiee-saint-medard-d-any-martin-rieux-et-son-cimetiere/ ccc502ab-48e4-4d8b-9152-d567beb51dda].

11. Sépulture 7004 : calibré à deux sigmas (Beta Analytic-539164).

12. Voir le dossier de l'Inventaire, en ligne [http://inventaire-patrimoine.cr-champagneardenne.fr/dossier/eglise-paroissiale-saint-benigne/ef4c2e45-d293-4b49-9dea-906e99d7b72d].

13. Le dessin d'Émile Gastebois laisse également voir un des arcs ayant pu donner sur la nef de l'état 2.

14. J. MARChAND, J.-C. RIVEREAU, J.-Y. SCANVIC et G. WEECKSTEEN, Carte géologique de la France à 1/50 000e, $n^{\circ}$ 223, Sézanne, notice explicative, Paris, 1965.

15. M. SALLE, «Dictionnaire géographique, historique et archéologique du département de la Marne ", in Mémoires de la Société d'agriculture, commerce, sciences et arts du département de la Marne, Paris, 1861-2, p. 13-381.

16. P. ROYER, Étude sommaire sur l'église de La Chapelle-Lasson, inédit.

17. C. LALORE, Liste des prieurés, commanderies et hôpitaux de l'ancien diocèse de Troyes d'après le pouillé de l'évêché de 1761, Arcis-sur-Aube, 1886, p. 7.

18. A.-M. LEgRAS, Les Commanderies des Templiers et des Hospitaliers de Saint-Jean de Jérusalem en Saintonge et en Aunis, Paris, 1983.

\section{INDEX}

Mots-clés : église, Moyen Âge, diagnostic archéologique, archéologie du bâti Index géographique : Marne 
AUTEUR

CÉDRIC ROMS

Inrap, UMR 8589-Lamop 